\title{
The differential role of repetitive negative thinking in the relationship between cognitive vs. behavioural OC symptoms and psychological distress
}

\author{
$\underline{\text { A Araujo }}^{1,2}$, AT Pereira ${ }^{1}$, C Cabaços ${ }^{1,2}$, MJ Soares ${ }^{1}$, AP Amaral ${ }^{3}$, A Macedo ${ }^{1,2}$ \\ ${ }^{1}$ Department of Psychological Medicine, Faculty of Medicine, University of Coimbra, Portugal \\ ${ }^{2}$ Psychiatry Department, Centro Hospitalar e Universitário de Coimbra, Portugal \\ ${ }^{3}$ Coimbra Health School, Polytechnic Institute of Coimbra, Portugal
}

\section{ITIRODUCTION}

Obsessive-CompulsiveDisorder(OCD) is characterized by obsessions (unwanted thoughts and/or images that cause significant distress) and compulsions (stereotyped behaviors and/or mental acts performed to reduce the distress). While obsessions are cognitive higher order processes, compulsions are more behavioural and less complex. The Portuguese validated version of the Maudsley Obsessional-Compulsive Inventory $(\mathrm{MOCl})$ assesses three independent but related factors: Doubting/Rumination (more cognitive); Checking and Cleaning (more behavioural). Repetitive Negative Thinking (RNT) is a style of thinking which is intrusive, difficult to control and perceived as unproductive.

Aim: To study a) the correlations between the $\mathrm{MOCl}$ dimensions and psychological distress; $b$ ) the mediator role of RNT on the relationship between the $\mathrm{MOCl}$ dimensions and psychological distress.

\section{METHOD}

Study approved by the Ethical Committee of the Faculty of Medicine, Coimbra

$>$ PARTICIPANT AND PROCEDURES

247 university students $(78.9 \%$ girls, mean aged $20.5 \pm 1.64$ years) answered the Portuguese versions of the following questionnaires.

$>$ Maudsley Obsessive-Compulsive Inventory (MOCl)

(Hodgson \& Rachman, 1977)

12 items answered on a 5-point Likert scale ranging from "Strongly disagree" to "Strongly agree".

$>$ Perseverative Thinking Questionnaire (Ehring et al., 2011)

60 items answered on a 5-point Likert scale ranging from "Strongly disagree" to "Strongly agree".

$>$ Depression, Anxiety and Stress Scale (DASS-21)

(Lovibond \& Lovibond, 1995)

21 items answered on a 4-point Likert scale ranging from "Did not apply to me at all" to "Applied to me very much, or most of the times".

\section{> STATISTICAL ANALYSES}

For statistical treatment of data SPSS 23.0 for Windows was used. Correlation/ mediation were performed using process for SPSS.

\section{RESULTS}

araujo.ana90@gmail.com

Table 1. Correlations between $\mathrm{MOCl}, \mathrm{RNT}$ and DASS-21

\begin{tabular}{|c|c|c|c|}
\hline & $\begin{array}{c}\text { Doubt/ } \\
\text { Rum }\end{array}$ & Check & Clean \\
\hline RNT & $.549^{\star \star}$ & $.307^{\star *}$ & $.238^{\star \star}$ \\
\hline Dep & $.397^{\star *}$ & $.240^{\star *}$ & $.179^{\star \star}$ \\
\hline Anx & $.446^{\star *}$ & $.244^{\star *}$ & $.155^{\star}$ \\
\hline Stress & $.495^{\star}$ & $.155^{\star}$ & NS \\
\hline
\end{tabular}

MORE BEHAVIOURAL LOWER ORDER PROCESSES

MORE COGNITIVE HIGHER ORDER PROCESSES

TABLE 1 All the MOCl dimensions presented significant positive correlations with RNT, Anxiety and Depression; Doubting/Rumination and Checking also correlated with Stress.

FIG 1 RNT fully mediated the relationship between Checking and Depression/Anxiety/Stress; $>$ and between Cleaning and Anxiety/Depression; but not between Doubting/Rumination and psychological distress.
Figure 1. Mediation between MOCI, RNT and DASS-21

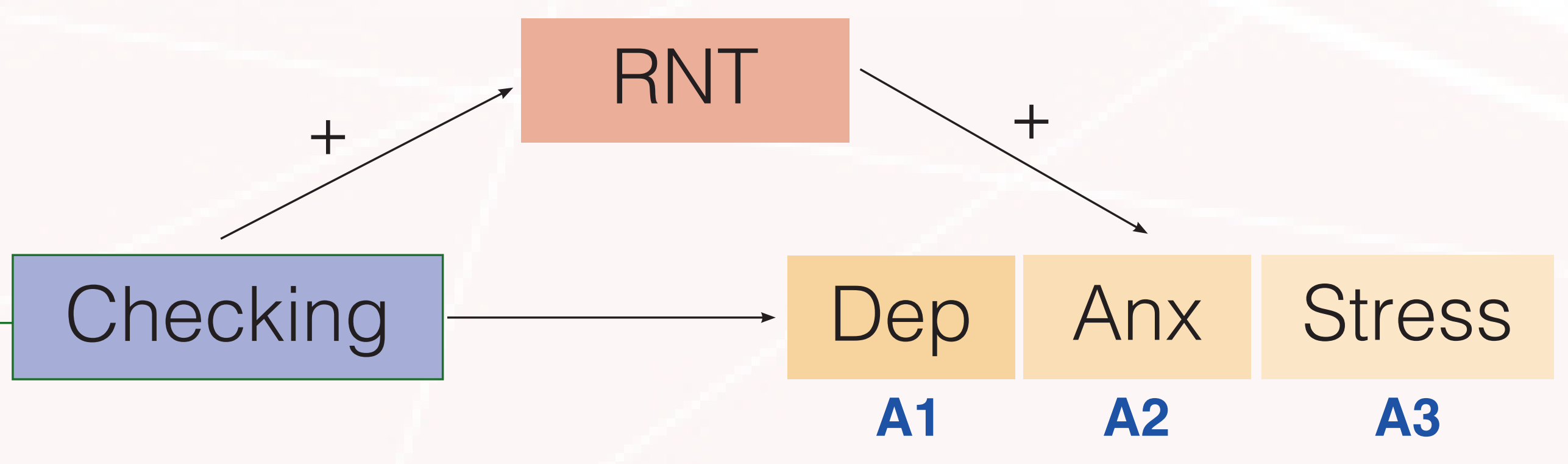

\section{RNT}

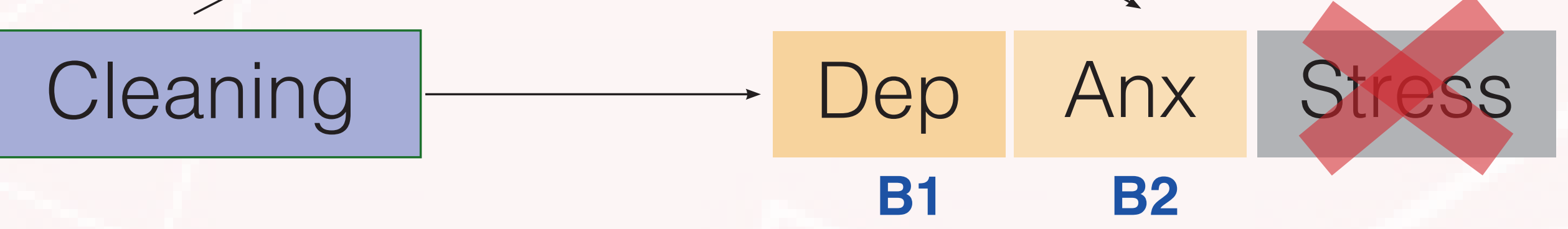

RNT

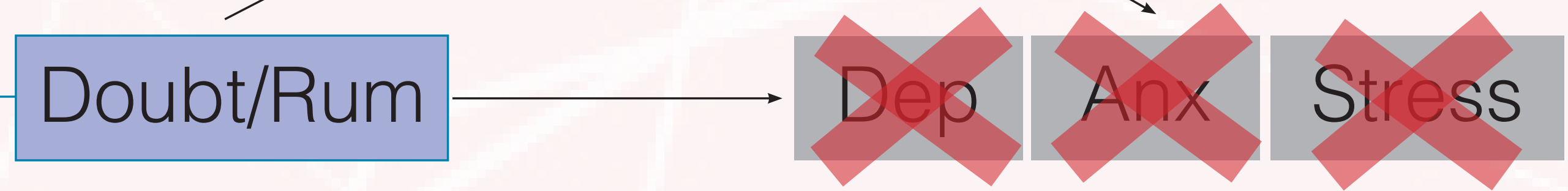

Doubt/Rum - Doubting/Rumination; Check - Checking; Clean Cleaning; RNT - Repetitve Negative Thinking; Dep- Depression; Anx - Anxiety

\section{DISCUSSION \& CONGLUSION}

Our results of OC symptoms in a non-clinical sample show that, unlike obsessions, lower order/compulsive dimensions may need concomitant egodystonic higher order/cognitive processes (eg.: RNT) to generate psychological distress.

This line of investigation may aid in the:

$>$ explanation and characterization OCD course and prognosis;

$>$ identification of OCD subtypes;

$>$ managment of OCD initial stages, when compulsions are predominant, and some of them are still egosyntonic.

\section{+ COMPULSIONS + OBSESSIONS}

